Notes

\title{
Selective Preconcentration and Separation of a Trace Amount of Copper(II) with Poly[ $\mathrm{N}$-(8-hydroxy-5-quinolylmethyl)-4-aminomethylstyrene] Resin
}

\author{
Xian Ren Chen*, Yuqi Feng*, Hisanori Imura*, Kazuhisa Hiratani** \\ and Kousaburo OHASHI* \\ *Department of Chemistry, Faculty of Science, Ibaraki University, Mito 310, Japan \\ **Material Technology and Industrial Engineering Research Institute, Tsukuba 305, Japan
}

Keywords Selective preconcentration, selective separation, copper(II), poly[ $N$-(8-hydroxy-5-quinolylmethyl)-4aminomethylstyrene] resin

The selective preconcentration and separation of tracemetal ions have been important subjects in analytical and environmental chemistry. Since chelating resins are characterized by a simple separation procedure and higher concentration factors, some new chelating resins have been synthesized in an effort to develop a selective separation methods for metal ions of interest. ${ }^{1}$

Several chelating resins, in which 8-quinolinol was immobilized on different matrices, have been prepared due to the potential ability to form stable metal complexes. $^{2,3}$

Warshawsky reported a new type of resin for copper(II), in which 8-quinolinol is bonded to a macroporous poly(styrene-divinylbenzene) copolymer through $-\mathrm{CH}_{2}-$ $\mathrm{NH}-\mathrm{CH}_{2}$ - bonding. ${ }^{4}$ However, no details concerning the adsorption behavior of copper(II) have been investigated. We have demonstrated that the adsorption rate of copper(II) on PQAS resin is dependent on the kinds of anions, and was accelerated by adding such anions as $\mathrm{SO}_{4}{ }^{2-}, \mathrm{NO}_{3}^{-}, \mathrm{Cl}^{-} .5$

The adsorption behavior of copper(II), manganese(II), cobalt(II), nickel(II), zinc(II), lead(II), palladium(II), platinum(II) and iron(III) was studied by a batch method. The preconcentration and preseparation of a trace amount of copper(II) by a column method was examined and applied to the preconcentration and determination of copper(II) in a tap-water sample.

\section{Experimental}

\section{Preparation of $P Q A S$ resin}

PQAS resin was synthesized by a reported method ${ }^{4}$ with some modifications. A $4.2 \mathrm{~g}$ of aminomethylpolystyrene resin (AMPS) prepared from poly(styrenedivinylbenzene) copolymer (10\% cross linking and $50-$ 300 mesh) was refluxed with $8.9 \mathrm{~g}$ of 5-chloromethyl-8quinolinol hydrochloride 6 in $250 \mathrm{~cm}^{3}$ of $0.1 \mathrm{~mol} \mathrm{dm}$ $\mathrm{HCl}$ for $6 \mathrm{~h}$. Analysis: $78.00 \% \mathrm{C}, 7.43 \% \mathrm{~N}, 7.41 \% \mathrm{H}$.
The incorporated 8-quinolinol groups were calculated to be $0.96 \mathrm{mmol} / \mathrm{g}$-resin.

Working solutions of metal ions were prepared by dissolving the metal salts of chloride, nitrate, and sulfate in $0.01 \mathrm{~mol} \mathrm{dm}^{-3}$ corresponding acids.

Water was purified by demineralization with a MILLI Q Labo (Nippon Milli Pore Co. Ltd.) after double distillation.

All of the other chemicals were of analytical reagent grade.

\section{Procedure for the batch method}

A $50 \mathrm{mg}$ sample of PQAS resin (100 - 350 mesh) and a $20-\mathrm{cm}^{3}$ portion of an aqueous solution of a metal ion $\left(2.0 \times 10^{-4} \mathrm{~mol} \mathrm{dm}^{-3}\right)$ were gently agitated in a $50-\mathrm{cm}^{3}$ vial for $10 \mathrm{~min}-6 \mathrm{~d}$. The copper(II) in an aqueous solution was determined using an atomic absorption spectrometer (AAS). The $\mathrm{pH}$ of the aqueous solution was adjusted by $\mathrm{HCl}, \mathrm{HNO}_{3}$ or $\mathrm{H}_{2} \mathrm{SO}_{4}$. The ionic strength was adjusted so as to be constant by the addition of sodium chloride, sodium nitrate, and sodium sulfate, in some cases. All of the experiments were performed in a thermostated room at $25^{\circ} \mathrm{C}$.

\section{Procedure for the column method}

A $500 \mathrm{mg}$ of PQAS resin (100-350 mesh) was packed into a Pyrex column $(0.5 \mathrm{~cm}$ i.d. and $6.5 \mathrm{~cm}$ in height). Then, a metal solution was passed through a PQAS resin column using a peristaltic pump at a flow rate of $0.92 \mathrm{~cm}^{3} \mathrm{~min}^{-1}$. The eluate was collected in 20 or $50 \mathrm{~cm}^{3}$ fractions each. Breakthrough curves for the adsorption of metal ions were obtained by measuring the metal ions in the eluate. Metal ions, except for platinum(II) and palladium(II), were eluted with $10 \mathrm{~cm}^{3}$ of $1.5 \mathrm{~mol} \mathrm{dm}^{-3}$ $\mathrm{H}_{2} \mathrm{SO}_{4}$. After the eluate was appropriately diluted with deionized water, metal ions were determined by AAS. 


\section{Results and Discussion}

\section{Adsorption isotherm for copper(II)}

A 50 -mg portion of the dry resin was gently agitated with $50 \mathrm{~cm}^{3}$ of a copper(II) $\left(5 \times 10^{-5} \mathrm{~mol} \mathrm{dm}{ }^{-3}-5 \times 10^{-2}\right.$ mol dm ${ }^{-3}$ ) solution at $\mathrm{pH} 2.0$ for $2 \mathrm{~h}-6 \mathrm{~d}$ in order to attain adsorption equilibrium. After the resin was filtered off, the adsorbed copper(II) was eluted with at least $10 \mathrm{~cm}^{3}$ of $1.5 \mathrm{~mol} \mathrm{dm}^{-3} \mathrm{H}_{2} \mathrm{SO}_{4}$, and was determined by AAS. A plot of $\log q v s$. $\log c$ gave a straight line, where $q$ and $c$ are the adsorbed copper(II) concentration and the residual concentration of copper(II) in an aqueous solution, respectively. The adsorption isotherm for copper(II) is a typical Freundlich isotherm. This type of the isotherm has often been observed in the adsorption of metal ions by a resin.?

\section{Adsorption behavior for metal ions by a batch method}

Figure 1 represents the adsorption curves of metal ions by a batch method. The $\mathrm{pH}$ was adjusted with $\mathrm{HCl}$. As reported in a previous paper ${ }^{5}$, the adsorption of the copper(II) on the PQAS resin was dependent on not only the $\mathrm{pH}$, but also on the kinds of acids used for the $\mathrm{pH}$ adjustment. In the cases of $\mathrm{H}_{2} \mathrm{SO}_{4}$, the copper(II) was completely adsorbed above $\mathrm{pH}$ 2.0. However, the adsorption decreased along with increases in the $\mathrm{pH}$ in the 2-4 range in the cases of $\mathrm{HNO}_{3}$ and $\mathrm{HCl}$ ( $c f$. Fig. 1). This unusual adsorption behavior of copper(II) on PQAS resin was ascribed to a difference in the adsorption rate, which depended on the anions in the aqueous solution. The increasing order of the rate was $\mathrm{NO}_{3}{ }^{-}$ $<\mathrm{Cl}^{-}<\mathrm{SO}_{4}{ }^{2-}$. Although copper(II) is almost completely adsorbed at pH 2.0, manganese(II) is not adsorbed at all. Nickel(II), cobalt(II) and zinc(II) are slightly adsorbed at pH 2.0. Platinum(II) and palladium(II) are completely adsorbed in the acid region below pH 1 .

The effect of sodium sulfate on the adsorption of metal ions was observed, as represented in Table 1 . In the presence of $0.1 \mathrm{~mol} \mathrm{dm}^{-3}$ sodium sulfate, manganese(II), cobalt(II) and nickel(II) were not adsorbed at all, and only $3 \%$ of zinc(II) was adsorbed. The adsorption of copper(II) was also affected by sodium sulfate, and slightly decreased from $100 \%$ to $97 \%$. Adsorbed metal

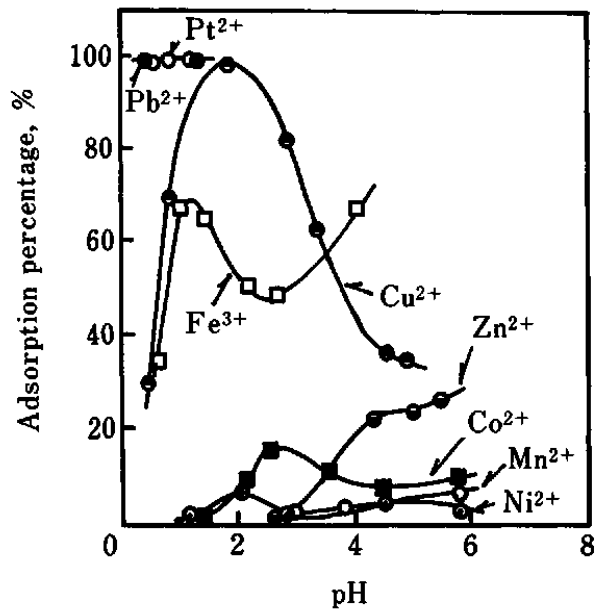

Fig. 1 Effect of the $\mathrm{pH}$ on the adsorption of $2.0 \times 10^{-4} \mathrm{~mol}$ $\mathrm{dm}^{-3}$ metal ion $\left(20 \mathrm{~cm}^{3}\right)$ onto PQAS resin $(50 \mathrm{mg})$ at $25^{\circ} \mathrm{C}$. Shaking time: $2 \mathrm{~h}$. The $\mathrm{pH}$ values were adjusted with $\mathrm{HCl}$.

ions, except for platinum(II) and palladium(II), were

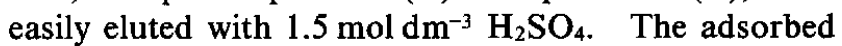
platinum(II) and palladium(II) were eluted with a $0.3 \mathrm{~mol} \mathrm{dm}^{-3}$ thiourea solution.

\section{Adsorption behavior of metal ions by a column method}

The effect of the flow rate of a feed solution containing $5.0 \times 10^{-7} \mathrm{~mol} \mathrm{dm}^{-3}$ copper(II) on the adsorption was investigated at pH 1.9, which was adjusted with $\mathrm{H}_{2} \mathrm{SO}_{4}$. More than $97 \%$ of the adsorption of copper(II) was obtained at flow rates of $0.62-1.92 \mathrm{~cm}^{3} \mathrm{~min}^{-1}$. Figure 2 shows breakthrough curves for the adsorption of copper(II), nickel(II), iron(III) and zinc(II) on PQAS resin. The concentration of metal ions in the feed solutions was $2.0 \times 10^{-4} \mathrm{~mol} \mathrm{dm}^{-3}$. The $\mathrm{pH}$ of the feed solutions was adjusted to $\mathrm{pH} 2.0$ with $\mathrm{H}_{2} \mathrm{SO}_{4}$. The copper(II) was completely adsorbed even at $185 \mathrm{~cm}^{3}$ of the feed solution. The adsorption quantity for copper(II) obtained by the column method is almost coincident with that obtained by the batch method. Whereas the breakthrough curve for iron(III) is fairly different from those for other metal ions, $45 \%$ of iron(III)

Table 1 Adsorption of metal ions onto PQAS resin $(50 \mathrm{mg})$ under various conditions

\begin{tabular}{lcllllllr}
\hline & $\mathrm{Mn}^{2+}$ & $\mathrm{Fe}^{3+}$ & $\mathrm{Co}^{2+}$ & $\mathrm{Ni}^{2+}$ & $\mathrm{Cu}^{2+}$ & $\mathrm{Zn}^{2+}$ & $\mathrm{Pd}^{2+}$ & $\mathrm{Pt}^{2+}$ \\
\hline $\mathrm{HCl}^{\mathrm{a}}$ & $1.7 \%$ & $48.1 \%$ & $9.1 \%$ & $3.9 \%$ & $99.0 \%$ & $0.3 \%$ & $100 \%$ & $100 \%$ \\
$(\mathrm{pH})$ & $(2.2)$ & $(2.1)$ & $(2.2)$ & $(2.2)$ & $(2.0)$ & $(2.2)$ & $(2.0)$ & $(2.0)$ \\
$\mathrm{HCl}^{\mathrm{b}}$ & $0 \%$ & $79.1 \%$ & $5.3 \%$ & $14.8 \%$ & $100 \%$ & $2.3 \%$ & $100 \%$ & $100 \%$ \\
$(\mathrm{pH})$ & $(2.2)$ & $(2.2)$ & $(2.2)$ & $(2.2)$ & $(2.0)$ & $(2.2)$ & $(2.4)$ & $(2.2)$ \\
$\mathrm{H}_{2} \mathrm{SO}_{4}{ }^{\mathrm{c}}$ & $0 \%$ & $82.4 \%$ & $0 \%$ & $0 \%$ & $97.0 \%$ & $3.0 \%$ & $100 \%$ & \\
$(\mathrm{pH})$ & $(2.1)$ & $(2.1)$ & $(1.9)$ & $(1.9)$ & $(2.1)$ & $(2.1)$ & $(2.1)$ & \\
$\mathrm{H}_{2} \mathrm{SO}_{4}{ }^{\mathrm{d}}$ & $0 \%$ & $82.4 \%$ & $0 \%$ & $2.7 \%$ & $98.0 \%$ & $3.0 \%$ & & \\
$(\mathrm{pH})$ & $(2.1)$ & $(2.0)$ & $(2.1)$ & $(2.1)$ & $(2.4)$ & $(2.0)$ & & \\
\hline
\end{tabular}

Metal ions: $20 \mathrm{~cm}^{3}$ of $2.0 \times 10^{-4} \mathrm{~mol} \mathrm{dm}^{-3}$. Shaking time: a, $2 \mathrm{~h} ; \mathrm{b}, 1 \mathrm{~h}$ (in the presence of $0.1 \mathrm{~mol} \mathrm{dm}^{-3}$ sodium chloride); $\mathrm{c}, 1 \mathrm{~h} ; \mathrm{d}, 1 \mathrm{~h}$ (in the presence of $0.1 \mathrm{~mol} \mathrm{dm}^{-3}$ sodium sulfate). 


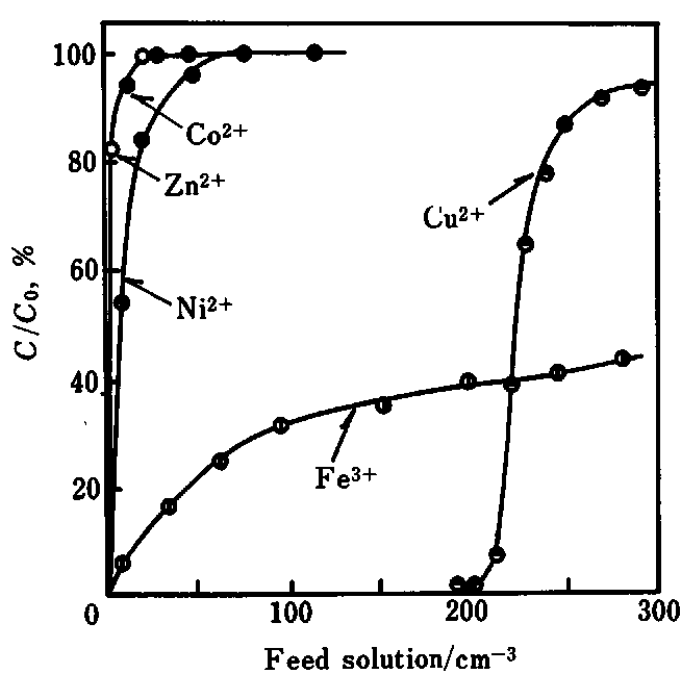

Fig. 2 Breakthrough curves for the adsorption of $2.0 \times 10^{-4} \mathrm{~mol}$ $\mathrm{dm}^{-3}$ metal ions onto PQAS resin at $\mathrm{pH} 1.9\left(\mathrm{H}_{2} \mathrm{SO}_{4}\right)$. Column: $500 \mathrm{mg}$ of PQAS resin was packed into a Pyrex glass tube $(0.5 \mathrm{~cm}$ i.d. and $6.5 \mathrm{~cm}$ in height $)$. Flow rate: $0.8 \mathrm{~cm}^{3} \mathrm{~min}^{-1} . \quad C_{0}$ and $C$ are the initial concentration of the feed solution and the concentration of the feed solution passed through the column, respectively.

in the feed solution was still adsorbed even after passing $280 \mathrm{~cm}^{3}$ of the feed solution. The unusual adsorption behavior of iron(III) may be due to the hydrolysis of iron(III). The amounts of the zinc(II), cobalt(II) and nickel(II) adsorbed were remarkably smaller than that of copper(II).

\section{Elution of copper(II) from the PQAS resin column}

The desorption behavior of copper(II) was investigated with $\mathrm{H}_{2} \mathrm{SO}_{4}$ and $\mathrm{HCl}$. About $98 \%$ of the copper(II) was eluted with $10 \mathrm{~cm}^{3}$ of $1.5-2.0 \mathrm{~mol} \mathrm{dm}^{-3}$ $\mathrm{H}_{2} \mathrm{SO}_{4}$. However, a $97.2 \%$ of the copper(II) adsorbed was eluted with as much as $40 \mathrm{~cm}^{3}$ of $4.0 \mathrm{~mol} \mathrm{dm}^{-3} \mathrm{HCl}$. The recovery of copper(II) in varying quantities was examined by passing a feed solution $\left(290-1000 \mathrm{~cm}^{3}\right)$ containing $2.0 \times 10^{-8} \mathrm{~mol} \mathrm{dm}^{-3}-2.0 \times 10^{-4} \mathrm{~mol} \mathrm{dm}^{-3}$ copper(II) and by subsequently eluting the adsorbed copper(II) with $1.5 \mathrm{~mol} \mathrm{dm}^{-3} \mathrm{H}_{2} \mathrm{SO}_{4}$.
The recovery was more than $98 \%$, independent of the copper(II) concentration in the feed solution when copper(II) adsorbed was eluted with $10 \mathrm{~cm}^{3}$ of $1.5 \mathrm{~mol}$ $\mathrm{dm}^{-3} \mathrm{H}_{2} \mathrm{SO}_{4}$.

\section{Application}

The present method was applied to the preconcentration and the determination of a trace amount of the copper(II) in a tap-water sample. The procedure was as follows. The tap-water sample was filtered with a membrane filter (TM-80 TOYO FILTER), the $\mathrm{pH}$ of the water was then adjusted to $1.9-2.0$ with $\mathrm{H}_{2} \mathrm{SO}_{4}$. A 2$\mathrm{dm}^{3}$ portion of the water sample was passed through a PQAS resin column $(0.5 \mathrm{~cm}$ i.d., $6.5 \mathrm{~cm}$ in height) at a folw rate of $0.92 \mathrm{~cm}^{3} \mathrm{~min}^{-1}$. The copper(II) adsorbed was eluted with $10 \mathrm{~cm}^{3}$ of $1.5 \mathrm{~mol} \mathrm{dm}^{-3} \mathrm{H}_{2} \mathrm{SO}_{4}$ and determined by AAS. The copper(II) concentration was determined to be $1.22 \mathrm{ppb}$ and $0.257 \mathrm{ppb}$ for the tap-water sample and for a distilled water sample, respectively. A blank experiment was carried out using purified water instead of a tap-water sample under the present experimental conditions. A blank value of copper(II) was $0.039 \mathrm{ppb}$ and negligibly smaller than the amount of copper(II) in the tap-water sample.

The present study was partially supported by a Grant-in-Aid for Scientific Research (C) (No. 05640675) from the Ministry of Education, Science and Calture.

\section{References}

1. K. S. Suresh and R. Jan, Coord. Chem. Rev., 59, 1 (1984).

2. J. R. Parrish, Chem. Ind., 1956, 137.

3. Z. Slovak, S. Slovakava and M. Smrg, Anal. Chim. Acta, 75, 127 (1975).

4. A. Warshawsky and R. Kalir, J. Appl. Polym. Sci., 24, 1125 (1979)

5. C. X. Ren, H. Imura, K. Hiratani and K. Ohashi, Bunseki Kagaku, 42, 707 (1993).

6. M. J. Kolobielski, J. Heterocycl. Chem., 3, 275 (1966).

7. S. Yasuda and K. Kawazu, Bunseki Kagaku, 37, T67 (1988).

(Received November 10, 1994) (Accepted February 27, 1995) 